\title{
A multiplex PCR assay for the detection of five influenza viruses using a dual priming oligonucleotide system
}

\author{
Xuezheng $\mathrm{Ma}^{1+}$, Huanzhou Xu ${ }^{1 \dagger}$, Lei Shi ${ }^{2}$, Pengfei Yang ${ }^{3}$, Liping Zhang ${ }^{1}$, Xiaohong Sun ${ }^{1}$, Wei Zhen ${ }^{1}$ \\ and Kongxin $\mathrm{Hu}^{1 *}$
}

\begin{abstract}
Background: A cost-effective, accurate and rapid simultaneous multiplex assay is required for testing and diagnoses of conventional and emerging viruses in clinical virology laboratories. We developed and optimized a dual priming oligonucleotide (DPO) multiplex PCR assay for detecting influenza viruses including seasonal H1N1, 2009 pandemic H1N1, H3N2, influenza B and H5N1.

Methods: The optimized multiplex DPO PCR was used to detect 233 clinical human samples. The results were compared to those obtained with RT-qPCR, conventional PCR and immunochromatographic assay.

Results: Specificity analysis revealed that the DPO PCR assay amplified each target virus without any crossamplification. Statistical analysis demonstrated that the multiplex DPO-PCR sensitivity was higher than for the immunochromatographic assay and lower than for GPCR, while no significant difference was observed compared with conventional PCR, when detecting influenza A and B. Additional experiments using the same sample panel indicated no significant differences between the number of positive samples detected by multiplex DPO PCR and RT-qPCR when applying a Cq with a value lower than 30 .

Conclusions: The five-targeted simultaneous multiplex DPO PCR assay could be easily adopted into routine practice. This approach is cost effective with a short running time, low technical requirements for the detection of influenza virus and early diagnosis in clinical laboratories.
\end{abstract}

Keywords: Dual priming oligonucleotide, DPO, Multiplex PCR, Influenza

\section{Background}

Influenza viruses are the major pathogens causing respiratory diseases with severe morbidity and mortality worldwide [1]. Novel and recombinant strains of influenza viruses have caused pandemics resulting in millions of deaths. The rapid detection of these viruses is essential for a medical response and infection control [1]. A low-cost and rapid identification of influenza types and subtypes in clinical patients is essential for initial clinical treatment and avoidance of antibiotic misuse, as well as prevention

\footnotetext{
*Correspondence: hukongxin@caiq.gov.cn

${ }^{\dagger}$ Equal contributors

'Institute of Health and Quarantine, Chinese Academy of Inspection and Quarantine, |No.A3, Gaobeidian North Road, Chaoyang District, Beijing 100123, China

Full list of author information is available at the end of the article
}

of influenza virus transmission, especially in resourcelimited regions [1].

Molecular assays are highly sensitive and specific for detecting influenza viruses such as rapid immune colloidal gold diagnostic tests, immunofluorescence, enzyme-linked immunosorbent assay (ELISA) and viral culture. Nucleic acid based tests for respiratory viruses are currently used as a rapid and sensitive diagnostic approach for clinical specimens. A cost-effective, accurate and rapid multiplex assay is highly desirable in clinical virology laboratories for testing and diagnosing common and emerging viruses. Even though the multiplex real time polymerase chain reaction (PCR) is a rapid and sensitive method for the detection of respiratory viruses, such assays are limited to a maximum of four multiplexed targets, and the high cost

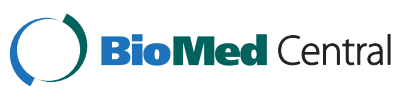

(C) 2015 Ma et al.; licensee BioMed Central. This is an Open Access article distributed under the terms of the Creative Commons Attribution License (http://creativecommons.org/licenses/by/4.0), which permits unrestricted use, distribution, and reproduction in any medium, provided the original work is properly credited. The Creative Commons Public Domain Dedication waiver (http://creativecommons.org/publicdomain/zero/1.0/) applies to the data made available in this article, unless otherwise stated. 
of reagents and equipment involved is particularly limiting for laboratories with low financial constraints [2].

Therefore, a novel dual priming oligonucleotide (DPO) technology was developed to solve these problems. The DPO primer contains two separate priming regions joined by a polydeoxyinosine linker, which assumes a bubble-like structure not involved in priming, but which delineates the boundary between two regions of the primer [3]. This structure confers distinct annealing properties on the two primer segments. The longer 5 '-segment initiates stable priming, while the short 3 '-segment determines targetspecific extension [3]. The advantage of DPO based PCR is the blocking extension of non-specifically primed templates under less than optimal PCR conditions [3]. DPO technology was commercialized and used in many recent studies to test different respiratory viruses [3]. Additionally, several studies have compared DPO based multiplex PCR with other rapid methods for the detection of influenza viruses. The results suggested that the DPO based multiplex PCR system had a higher sensitivity and specificity than the other methods tested [4-7]. However, most of these recent studies, including those using commercial DPO based rapid detection kits, tested numerous different respiratory viruses or different types of influenza viruses. Only one commercial kit (Seeplex ${ }^{\odot}$ Influenza A/B OneStep Typing, Seegene, Seoul, Korea) can simultaneously detect influenza A, B and subtypes of influenza A including 2009 pandemic H1 and Human Seasonal Influenza A (H1 and H3). Recently, the live poultry market has posed a high risk for human infection following the avian infection in Beijing, China [8]. The highly pathogenic avian influenza H5N1 was identified in local poultry and wild birds is enzootic in China [8]. Therefore, it is important to develop a rapid and simple method to detect avian influenza viruses. To our knowledge, no previous study has reported the development of a DPO multiplex assay for the simultaneous detection of influenza A, B and subtypes of influenza A including H5N1.
The purpose of this study was to develop and optimize a DPO multiplex PCR assay for detection of influenza A and $B$ viruses, including the influenza $A$ subtypes, such as seasonal H1N1, 2009 pandemic H1N1, H3N2, and avian influenza H5N1. Additionally, the study compared and evaluated DPO PCR, qPCR, conventional PCR and immunochromatographic assay for the detection of influenza viruses in clinical specimens.

\section{Methods \\ Clinical samples}

This study randomly screened 233 clinical specimens from feverish patients including human oropharyngeal swabs, nasopharyngeal swabs and sputum from Chinese Academy of Inspection and Quarantine, Center for $\mathrm{Di}$ sease Control of China, Beijing, China and the Shenzhen International Travel Health Care Center. Two H5N1 specimens were obtained from avian species from the Center for Disease Control of China. Additionally, 59 respiratory samples including parainfluenza viruses $1 / 2 / 4$ (PIV1/ 2/4), human rhinovirus (HRV), human metapneumovirus (hMPV), adenovirus (ADV), coronavirus 229E (CoV229E), respiratory syncytial virus $\mathrm{A} / \mathrm{B}$ (RSV $\mathrm{A} / \mathrm{B}$ ) and bocavirus $(\mathrm{BoV})$ were collected to assess the specificity of the multiplex DPO assay.

\section{DPO primer design}

DPO is a primer system for PCR that contains a bubblelike polydeoxyinosine linker that separates a single primer into two unequal regions. The five influenza virus sequences were aligned by MEGA5.1 [9]. Five pairs of DPO primers were designed based on the specific regions for each virus (Table 1). The optimal numbers of polydeoxyinosine for each DPO primer was determined by testing 3-8 poly (I) linkers for each target virus. The amplified products were analyzed by $2.0 \%$ agarose (Biowest, Hongkong, China) gel electrophoresis.

Table 1 DPO primers used for multiplex DPO PCR

\begin{tabular}{|c|c|c|c|}
\hline Virus & Target gene & Primer sequence $\left(5^{\prime}-3^{\prime}\right)$ & Amplicon size (bp) \\
\hline \multirow[t]{2}{*}{ H1N1 pdm09 } & $\mathrm{HA}$ & F:TAGTGCTGACCAACAAAGTCTCTAIIIIIATGCAG & 231 \\
\hline & & R:GCATTTCTTTCCATTGCGAATGCIIIIITCGGTAC & \\
\hline \multirow[t]{2}{*}{ sH1N1 } & $\mathrm{HA}$ & F:TGCGAATYACTGATTTCCAAGGAIIIIIGGTCCTA & 193 \\
\hline & & R: CTCCGGTTACRGTGTGGTGGGGIIIIAGCTCTCT & \\
\hline \multirow[t]{2}{*}{ H3N2 } & $\mathrm{HA}$ & F:ACGCTGTGCCTTGGGCACCATGCAIIIIIAAACGG & 537 \\
\hline & & R:GTCMTTGTCCGTACCCGGGTGGTGIIIIICCCAAA & \\
\hline \multirow[t]{2}{*}{ H5N1 } & HA & F:GAGAGATTGTAGTGTAGCTGGATIIIIICTCGGAA & 328 \\
\hline & & R:CTTTATTGTTGGGTATGTRCTGTTIIIITGATAAGCC & \\
\hline \multirow[t]{2}{*}{ FluB } & PB1 & F:TTGGCTATGACTGAAAGAATAACCAIIIIAGCCCA & 401 \\
\hline & & R:GCATTAACAAATAGAGCAAAATCATIIIIIGATTGC & \\
\hline
\end{tabular}




\section{Viral RNA extraction and CDNA synthesis}

All clinical samples were concentrated and enriched by a virus concentration device to increase the virus load. Viral RNA was extracted from viral solutions using the QIAamp Viral RNA Mini Kit (Qiagen, Germany) following the manufacturer's specifications. A volume of $140 \mu \mathrm{l}$ of virus solution was mixed with $560 \mu \mathrm{l}$ buffer AVL-carrier RNA and incubated for $10 \mathrm{~min}$ at room temperature. After adding $560 \mu \mathrm{l}$ ethanol (100\%), the solution was mixed thoroughly by pulse-vortexing and then transferred to a spincolumn. After a series of washing and drying steps, $60 \mu \mathrm{l}$ of RNase-free water was used to elute RNA, which was stored at $-70^{\circ} \mathrm{C}$. The master mix for reverse transcription was prepared using a reverse transcription system (Promega, USA) under the following conditions: a mixture of $5 \mu \mathrm{l}$ RNA template, $1 \mu \mathrm{l}$ Random primer and $2 \mu$ l RNase-free water was denatured at $95^{\circ} \mathrm{C}$ for $2 \mathrm{~min}$ and cooled on ice for $2 \mathrm{~min}$. Then $4 \mu \mathrm{l}$ of $\mathrm{MgCl}_{2}(25 \mathrm{mM}), 2 \mu \mathrm{lNTPs}$ $(10 \mathrm{mM}), 2 \mu \mathrm{l}$ reverse transcription $10 \times$ buffer, $30 \mathrm{U}$ of AMV reverse transcriptase, $25 \mathrm{U}$ of RNasin ribonuclease inhibitor and nuclease-free water were added to a final volume of $20 \mu \mathrm{l}$. Subsequently, the mixture was incubated at $42^{\circ} \mathrm{C}$ for $90 \mathrm{~min}$ and $72^{\circ} \mathrm{C}$ for $10 \mathrm{~min}$. Finally, the cDNA was stored at $-20^{\circ} \mathrm{C}$.

\section{Multiplex DPO PCR protocol}

Multiplex DPO PCR reactions contained $1.5 \mathrm{U}$ of Takara Taq (Takara Bio, Dalian, China), $2.5 \mu \mathrm{l}$ of $10 \times$ PCR buffer, $2.0 \mathrm{mM} \mathrm{Mg}^{2+}$ and $250 \mu \mathrm{M}$ dNTPs. The optimal concentration of DPO primer mix are listed in Table 2. 2009 pandemic $\mathrm{H} 1 \mathrm{~N} 1$, seasonal $\mathrm{H} 1 \mathrm{~N} 1, \mathrm{H} 3 \mathrm{~N} 2$ and $\mathrm{H} 5 \mathrm{~N} 1$ primers at a concentration of $0.8 \mu \mathrm{M}$ and influenza B primers at a concentration of $1.6 \mu \mathrm{M}, 2 \mu \mathrm{l} \mathrm{cDNA}$ and nuclease-free water were added to a total volume of $25 \mu \mathrm{l}$. The amplification conditions of the multiplex PCR were as follows: pre-denaturation step for $5 \mathrm{~min}$ at $94^{\circ} \mathrm{C}, 40$ cycles of denaturation at $94^{\circ} \mathrm{C}$ for $30 \mathrm{~s}$, annealing at $60^{\circ} \mathrm{C}$ for $30 \mathrm{~s}$, extension at $72^{\circ} \mathrm{C}$ for $1 \mathrm{~min}$, followed by a final extension step at $72^{\circ} \mathrm{C}$ for $10 \mathrm{~min}$. The multiplex DPO PCR was performed with an Applied Biosystems ${ }^{\circ} 2720$ Thermal Cycler (Life Technologies, NY, USA). The amplified products were analyzed by $2.0 \%$ agarose gel electrophoresis.

\section{Analytical sensitivity and specificity}

The partial HA and PB1 gene sequences of each virus (seasonal H1N1, CY082460, nt 250-442; 2009 pandemic

Table 2 Optimal DPO primer mix concentrations

\begin{tabular}{llllll}
\hline Component & $\begin{array}{l}\text { H1N1 } \\
\text { pmd09 }\end{array}$ & $\begin{array}{l}\text { Seasonal } \\
\text { H1N1 }\end{array}$ & H3N2 & H5N1 & Influenza B \\
\hline Forward Primer $(\mu \mathrm{M})$ & 20 & 20 & 20 & 20 & 40 \\
Reverse Primer $(\mu \mathrm{M})$ & 20 & 20 & 20 & 20 & 40 \\
$25 \times$ primer mix $(\mu \mathrm{M})$ & 0.8 & 0.8 & 0.8 & 0.8 & 1.6 \\
\hline
\end{tabular}

H1N1, CY087016, nt 616-846; H3N2, CY091581, nt 96-632; H5N1, AB598119, nt 210-537; influenza B, CY069569, nt 955-1355) were synthesized and inserted into pGM-T (Tiangen, China) to construct five specific plasmids. These plasmids were then in vitro transcribed using the RiboMax ${ }^{\mathrm{Tm}}$ Large Scale RNA Production SystemT7 according to the manufacturer's instructions (Promega, USA). The RNA concentration were detected by spectrophotometer (NanoDrop, Delaware, USA) and then reverse-transcribed to $\mathrm{CDNA}$ as previous instruction (Promega, USA). The initial concentration of sH1N1, H1N1pdm09, H3N2, H5N1 and FluB were $1.3 \times 10^{11}$ copies $/ \mathrm{ml}, 5.7 \times 10^{10}$ copies $/ \mathrm{ml}, 6.2 \times 10^{10}$ copies $/ \mathrm{ml}, 1.3 \times$ $10^{10}$ copies $/ \mathrm{ml}$ and $3.5 \times 10^{10}$ copies $/ \mathrm{ml}$, respectively.

A ten-fold serial dilution of plasmid DNA was used to compare the sensitivity levels of the multiplex PCR and the single conventional PCR for amplifying each type of influenza. Then, a pooled solution of all five templates was diluted in series $\left(10^{7}-10^{1}\right.$ copies $\left./ \mathrm{ml}\right)$, and detected by multiplex DPO primers to determine the sensitivity. The specificity test comprised the five pooled templates amplified by each pair of DPO primers individually. Additionally, the measurement of one-step multiplex DPO PCR specificity was determined using eight respiratory viral RNA preparations: PIV1/2/4, HRV, hMPV, ADV, CoV229E, RSVA, RSVB and BoV.

\section{Sequencing}

The amplified conventional PCR products were sequenced to evaluate the specificity of the assay. Sequencing was performed using an ABI PRISM 3730 DNA Sequencer and sequences obtained were confirmed by the GenBank (National Center for Biotechnology Information) database with the Basic Local Alignment Search Tool (BLAST).

\section{RT-qPCR}

Total RNA from $140 \mu$ l clinical samples was separately extracted using QIAamp Viral RNA Mini kit (Qiagen, Valencia, CA, USA). RNA was eluted in $60 \mu \mathrm{l}$ of elution buffer and stored at $-80^{\circ} \mathrm{C}$. The singleplex RT-qPCR was performed using an Applied Biosystems ${ }^{\circ} 7500$ Real-Time PCR System (Applied Biosystems ${ }^{\circ}$ by Life Technologies, NY, USA) to test all clinical samples. The primers and probes used for the RT-qPCR were suggested by WHO Information for Molecular Diagnosis of Influenza Virus in Humans - update (November 2012) [10]. RT-qPCR was performed with an AgPath-ID ${ }^{\mathrm{ma}}$ One-Step RT-PCR Kit (Ambion, Applied Biosystems ${ }^{\circ}$ by Life Technologies, NY, USA). A total of $25 \mu \mathrm{l}$ RT-qPCR mixture included $12.5 \mu \mathrm{l}$ of $2 \times$ RT-PCR buffer, $1 \mu \mathrm{l} 25 \times$ RT-PCR enzyme mix, $0.5 \mu \mathrm{l}$ one-step RT-PCR master kit (Qiagen), $0.5 \mu \mathrm{l}(20 \mu \mathrm{M})$ of each primer, $0.3 \mu \mathrm{l}(10 \mu \mathrm{M})$ of probe, $4.7 \mu \mathrm{l}$ of nuclease-free water and $5 \mu \mathrm{l}$ of extracted RNA. The thermocycling parameters were as follows: reverse 
transcription (RT) at $45^{\circ} \mathrm{C}$ for $10 \mathrm{~min}$, $\mathrm{RT}$ inactivation at $95^{\circ} \mathrm{C}$ for $10 \mathrm{~min}$ and fluorescence detection for 40 cycles at $95^{\circ} \mathrm{C}$ for $15 \mathrm{sec}$ and annealing at $60^{\circ} \mathrm{C}$ for 45 sec. RT-qPCR data was analyzed by SDS software from Applied Biosystems ${ }^{\oplus}$. Amplification curves were evaluated by the threshold line being placed above the background signal, intersecting the initial exponential phase of the curve. Amplification of influenza virus was observed at a quantification cycle $(\mathrm{Cq})$ value of 35 . A test result was considered positive when a well-defined curve that crossed the threshold cycle within 35 cycles was observed.

\section{Conventional PCR protocol}

The detection kit used in our study was from Takara Biotechnology (Dalian) Co., Ltd. A $25 \mu$ reaction system was set up containing $2 \mu \mathrm{l}$ template RNA, $0.125 \mu \mathrm{l}$ Takara Taq $(250 \mathrm{U} / \mu \mathrm{l}), 0.5 \mu \mathrm{l}$ of each primer $(10 \mu \mathrm{M})$, $2 \mu \mathrm{l}$ of $10 \times$ PCR Buffer (Mg2+ Plus), dNTP mixture $(2.5 \mathrm{mM})$ and $17.4 \mu \mathrm{l}$ RNase free water. The test was performed using a Applied Biosystems ${ }^{\ominus} 2720$ Thermal Cycler. The PCR reaction was amplified under the following conditions: pre-denaturation step for $5 \mathrm{~min}$ at $94^{\circ} \mathrm{C}, 40$ cycles of denaturation at $94^{\circ} \mathrm{C}$ for $30 \mathrm{~s}$, annealing at $60^{\circ} \mathrm{C}$ for $30 \mathrm{~s}$, extension at $72^{\circ} \mathrm{C}$ for $1 \mathrm{~min}$, followed by a final extension step at $72^{\circ} \mathrm{C}$ for $10 \mathrm{~min}$. The PCR was performed by Applied Biosystems ${ }^{\oplus} 2720$ Thermal Cycler. The amplified products were analyzed by $2.0 \%$ agarose gel electrophoresis.

Alere BinaxNOW ${ }^{\circledR}$ Influenza A\&B Card rapid detection assay The colloidal gold immunochromatographic assay was applied for the detection of influenza A and B. The procedure followed the manufacturer's instructions.

Comparison of multiplex DPO, conventional and RT-qPCR, and Alere BinaxNOW ${ }^{\circledR}$ Influenza A\&B Card rapid detection assay for influenza $A$ and $B$

All clinical specimens were screened for seasonal H1N1, 2009 pandemic H1N1, H3N2, influenza B and avian influenza $\mathrm{H} 5 \mathrm{~N} 1$ by multiplex DPO PCR. RT-qPCR and conventional PCR for the detection of influenza $A$ and $B$ were used to validate the multiplex DPO PCR method and results were compared to those obtained by immunochromatographic assay.

\section{Statistical analysis}

Statistical analysis was performed by SPSS18.0 (IBM, New York, USA). The chi-squared test was used to analyze data and a $P$ value of $<0.05$ was considered statistically significant.

\section{Ethical statement}

The study was conducted according to the protocol approved by the Human Research Ethics Committee, Chinese Academy of Inspection and Quarantine in compliance with the provisions for human research in the Helsinki Declaration (ES-0823696/2014/376HQ). Written informed consent was obtained from all the participants.

\section{Results}

Optimized numbers of poly I linkers in DPO primer design and annealing temperature for multiplex DPO PCR The number of poly (I) in DPO primers impacts both the sensitivity and specificity of the DPO PCR amplification. This study therefore tested various numbers of poly (I) linkers, with five linkers proving optimal (Figure 1). Because the influenza viral gene are highly mutable, four annealing temperatures $(T m)$ were selected and applied to different concentrations of the mixed templates. When the $\mathrm{Tm}$ was $46^{\circ} \mathrm{C}$ and $50^{\circ} \mathrm{C}$, the lowest template concentration was $10^{4}$ viral particles/ml (Figure 2). When the $T m$ was increased to $55^{\circ} \mathrm{C}$, faint bands $\left(10^{3}\right.$ viral particles $/ \mathrm{ml}$ ) were observed. When the $T m$ reached to $60^{\circ} \mathrm{C}$, distinct bands indicated the lowest concentration of mixed template was $10^{3}$ viral particles $/ \mathrm{ml}$ for multiplex DPO PCR.

\section{Multiplex DPO PCR sensitivity}

A 10-fold dilution series was used to determine the lowest concentration detected by the multiplex DPO PCR. This was found to be $10^{3}$ copies/ml for $\mathrm{sH} 1 \mathrm{~N} 1$, H1N1pdm09, H3N2, H5N1 and FluB; although very faint bands were also observed in lane 6 for $10^{2}$ viral particles/ml (Figure 3). The sizes of the amplified product were detected by $2 \%$ agarose gel, and determined to be $537 \mathrm{bp}$ for H3N2, $401 \mathrm{bp}$ for FluB, $328 \mathrm{bp}$ for H5N1, 231 bp for H1N1pdm09, and 193 bp for sH1N1. Although a pooled mixture of the five virus templates was used for amplification by the multiplex primers, no cross-amplification was observed.

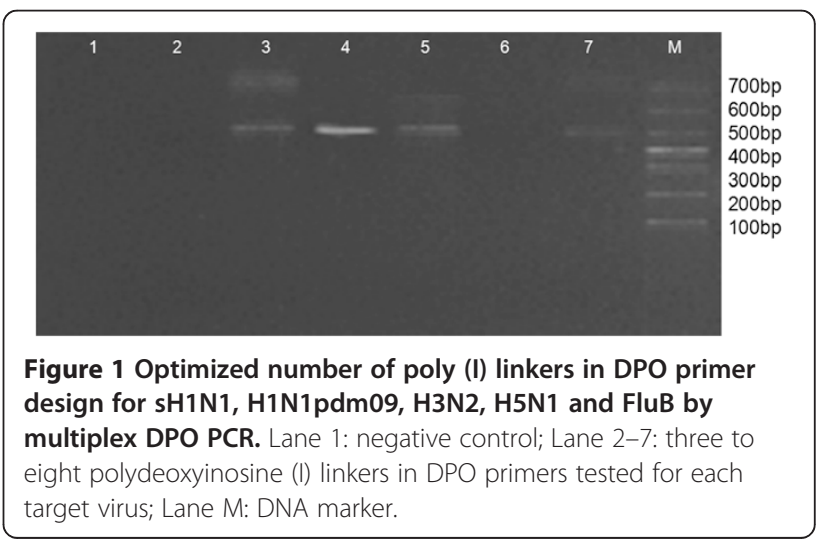



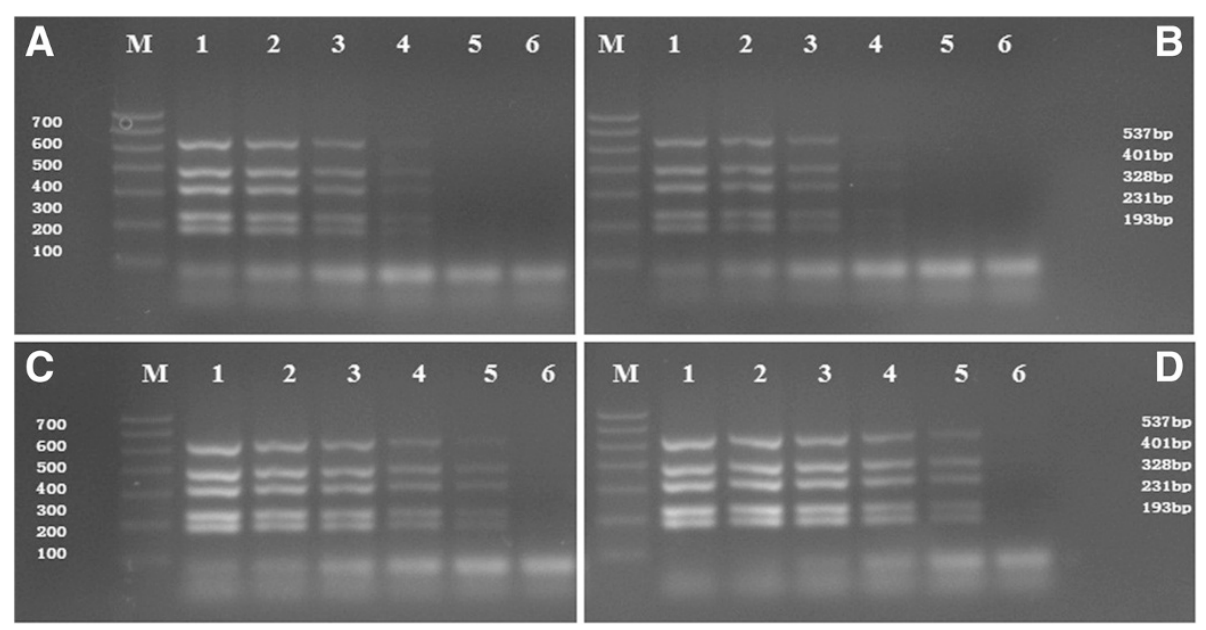

Figure 2 Optimized annealing temperature for sH1N1, H1N1pdm09, H3N2, H5N1 and FluB by multiplex DPO PCR. (A: Tm $=46^{\circ} \mathrm{C}$;

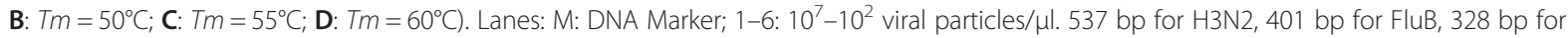
H5N1, 231 bp for H1N1pdm09, and 193 bp for sH1N1.

\section{Multiplex DPO PCR specificity}

A single pair of DPO primers was used to amplify sH1N1, H1N1pdm09, H3N2, H5N1 and FluB mixture to test the assay specificity. Each primer set produced a single amplified band without non-specific amplification (Figure 4A). Additionally, the multiplex PCR primers were used to amplify each target virus template. Agarose gel analysis confirmed the multiplex PCR amplification for each lane containing sH1N1, H1N1pdm09, H3N2, H5N1 and FluB, respectively (Figure 4B). No amplification was observed for PIV1/2/4, HRV, hMPV, ADV, CoV229E, RSVA, RSVB or BoV when using the multiplex DPO primers (Figure 4C).

\section{Screening of clinical specimens by multiplex DPO PCR}

Using singleplex RT-qPCR as a standard, the overall positives were 153 . Of 153 positive specimens, 84 were identified as influenza A and 69 as influenza B. Figure 5 shows the selected multiplex DPO PCR result for clinical sample detection. The percentage of influenza A and B positive samples detected by multiplex DPO PCR in concordance with real time RT-PCR was $66.67 \%$ and $62.32 \%$, respectively (Table 3 ).

DPO PCR positive influenza A and B specimens were assessed and confirmed by sequencing to prevent falsepositive or false-negative results.

\section{Comparison of different methods for the detection of influenza $A$ and $B$}

Multiplex DPO PCR, RT-qPCR, conventional single-target PCR and commercial colloidal gold immunochromatographic assay Alere BinaxNOW ${ }^{\circ}$ Influenza A\&B Card (Alere, CA, USA) were used to detect influenza A and B. The selected test results for qPCR and immunochromatographic assay are shown in Figures 6 and 7, respectively. The order of positive detection efficiency from highest to lowest was RT-qPCR, multiplex DPO PCR, conventional PCR and immunochromatographic assay (Figure 8). The

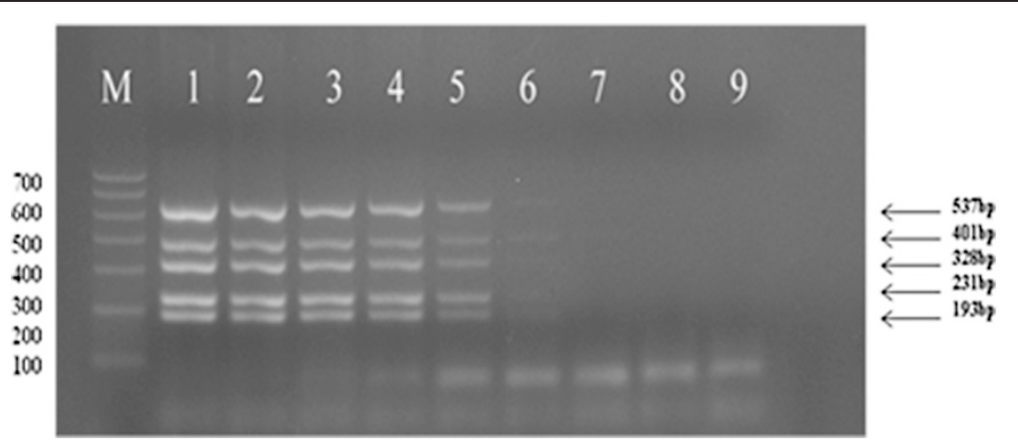

Figure 3 Detection sensitivity of sH1N1, H1N1pdm09, H3N2, H5N1 and FluB by multiplex DPO PCR. Lanes: M: DNA Marker; 1-8: 107 -10 viral particles/ml; 9: negative control. 537 bp for H3N2, 401 bp for FluB, 328 bp for H5N1, 231 bp for H1N1pdm09, and 193 bp for sH1N1. 


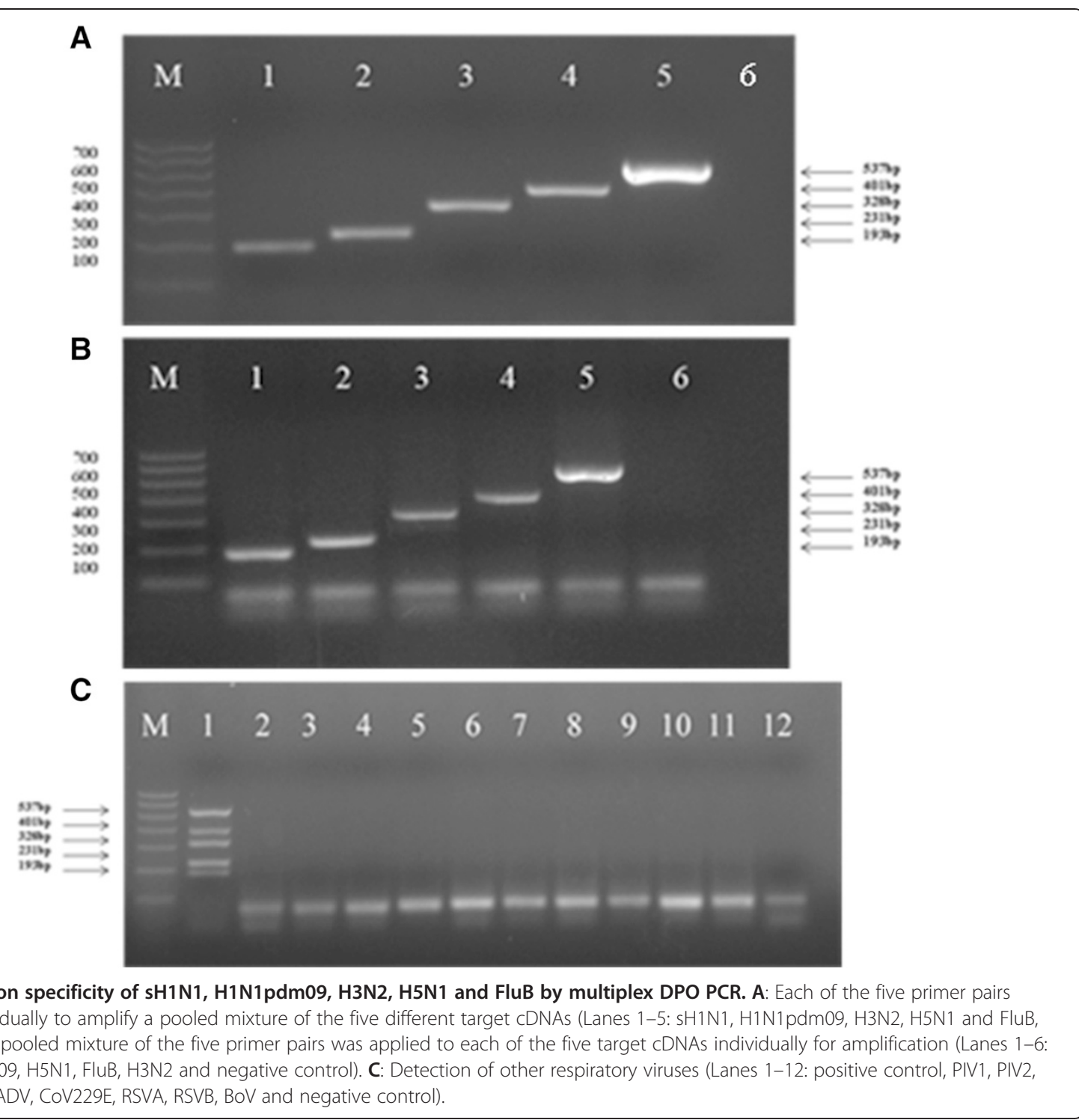

efficacy differences between DPO PCR and qPCR for sH1H1, H1N1pdm09, H3N2, H5N1and FluB are shown in Figure 9. Multiplex DPO PCR displayed 70\% correlation with qPCR positive results for influenza $\mathrm{A}$, while influenza B results showed lower correlation with qPCR. qPCR positive results that were inconsistent with multiplex DPO PCR samples were selected for further testing and the expected $\mathrm{Cq}$ was recorded. Figure 10 shows that different numbers of positive samples were observed for DPO PCR and RT-qPCR when using three different ranges of $\mathrm{Cq}$ values. When $\mathrm{Cq}$ was less than 25 or in the range of 25-30, no difference was observed between DPO and $\mathrm{qPCR}$ in terms of the number of positive samples detected. When the Cq value was between 30 to 35, the number of positive results obtained by $\mathrm{qPCR}$ were greater than those for DPO PCR.

\section{Statistical analysis of different detection methods}

Statistical analysis showed that the sensitivity of the multiplex DPO assay was lower than for qPCR $(P<0.05)$, higher than for the colloidal gold immunochromatographic assay $(P<0.05)$, but not significantly different from conventional PCR $(P>0.05)$ (Figure 8$)$. When the Cq value was lower than 30 , no significant difference between multiplex DPO PCR and qPCR when comparing the positive results (Figure 10).

\section{Discussion}

A rapid, accurate and low-cost diagnostic tool for influenza detection is important for the control and prevention of annual influenza pandemics. A previous study described the development of a multiplex DPO PCR assay for the simultaneous and specific detection 


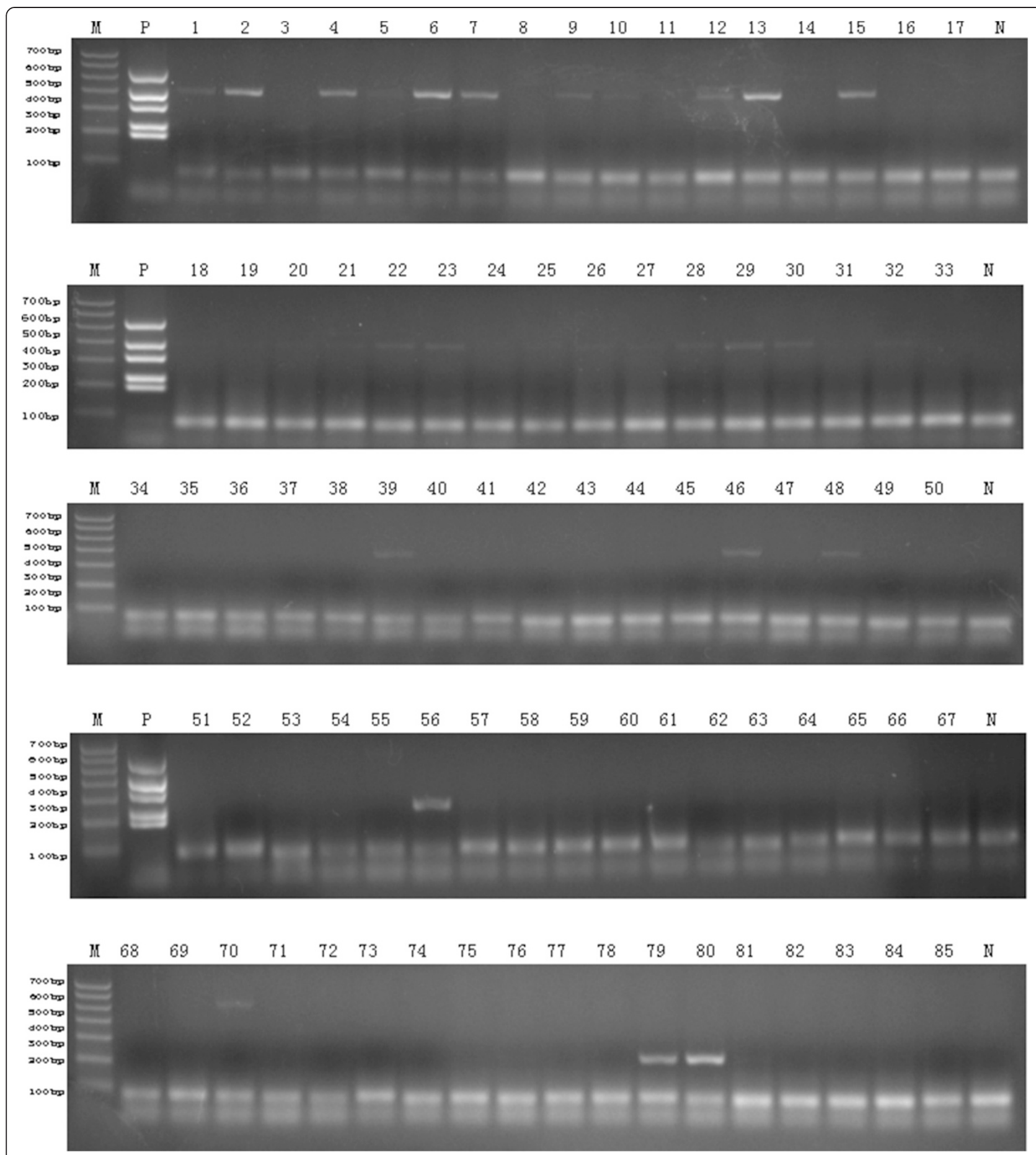

Figure 5 The selected result of clinical samples by multiplex DPO PCR. Selected 85 screening result for influenza A and B detection using multiplex DPO PCR. Lane M: DNA marker; lane P: positive control; lane N: negative control.

of influenza A and B [11]. Here, we demonstrated the optimization of one-step multiplex DPO PCR for use as a sensitive and specific method to detect seasonal H1N1, 2009 pandemic H1N1, H3N2, and avian influenza H5N1.
Optimized annealing temperature for multiplex DPO PCR For most conventional PCR methods, a lower annealing temperature gives a higher sensitivity, which might increase the nonspecific amplification rate [5,12]. However, if the $T m$ is increased to maintain high specificity, then 
Table 3 Clinical specimens tested by qPCR and multiplex DPO PCR

\begin{tabular}{|c|c|c|c|c|c|c|}
\hline & \multicolumn{4}{|c|}{ Positive influenza A } & \multirow{2}{*}{$\begin{array}{l}\text { Positive } \\
\text { influenza B }\end{array}$} & \multirow{2}{*}{$\begin{array}{l}\text { Negative } \\
\text { samples }\end{array}$} \\
\hline & Seasonal H1N1 & 2009 pandemic H1N1 & H3N2 & $\mathrm{H} 5 \mathrm{~N} 1$ & & \\
\hline RT-qPCR & 14 & 39 & 29 & 2 & 69 & 80 \\
\hline Multiplex DPO PCR & 13 & 25 & 16 & 2 & 43 & 134 \\
\hline Positive Concordant Percentage & \multicolumn{4}{|l|}{$56(66.67 \%, 56 / 84)$} & $43(62.32 \%, 43 / 69)$ & $\ldots$ \\
\hline
\end{tabular}

the test sensitivity will in turn decrease. In this study, when the $\operatorname{Tm}$ reached $60^{\circ} \mathrm{C}$, no nonspecific amplification was observed and the test was shown to be highly sensitive compared with the other methods tested.

\section{Multiplex DPO PCR is sensitive and specific for the detection of influenza $A$ and $B$}

Template concentrations as low as $10^{2}$ viral particles $/ \mathrm{ml}$ were detectable using this method, with a robust test result obtained by multiplex DPO PCR at a concentration of $10^{3}$ viral particles $/ \mathrm{ml}$ when applied to a mixture of influenza virus templates. A previous study reported the sensitivity of $10^{2}$ copies per reaction for each type of virus; however, the concentration of the mixture of viruses amplified was not stated [5,6]. The DPO primer amplified PCR products for seasonal H1N1, 2009 pandemic H1N1, $\mathrm{H} 3 \mathrm{~N} 2$ and avian influenza H5N1 were clearly visualized by agarose gel electrophoresis without non-specific amplification or false-positive bands (Figure 3).

Test specificity was investigated in three ways. Each DPO primer pair was individually applied towards amplifying a pooled mixture of the five influenza viruses tested, and a single distinct band was produced for each template (Figure 4A). Secondly, a multiplex PCR primer pool was applied towards amplifying each target template individually, and yet again, no non-specific bands were detected (Figure 4B). Furthermore, no non-specific amplification was observed when applying the multiplex DPO PCR primers to other, non-targeted virus templates (Figure 4C). A previous study stated that the DPO system prevents non-specific amplification without inhibiting the efficient amplification of the target bands [11]. In this study, the high sensitivity and specificity were consistent with previous studies $[5,6]$.

\section{Evaluation of DPO PCR performance to detect viruses in clinical specimens}

This study evaluated the multiplex DPO PCR system and compared it with qPCR using 233 respiratory clinical specimens. All clinical samples were screened by singleplex qPCR for the separate detection of influenza A and $\mathrm{B}$. Positive specimens were defined as those reaching a florescent threshold value $(\mathrm{Cq}<35)$, and were used as standards. Based on the statistical results, the multiplex DPO PCR showed no significant difference in sensitivity or specificity with conventional single PCR, and had a higher sensitivity and specificity than the colloidal gold immunochromatographic assay.

Several previous studies have evaluated different respiratory virus diagnostic tests using the DPO-based commercial kit including Seeplex ${ }^{\oplus}$ RV15 ACE Detection kit and RV 12 Detection kit (Seegene). Their results indicated that the sensitivity and specificity of the Seeplex DPO based PCR system were $83.3 \%$ and $95.2 \%$, respectively [12]. Cho

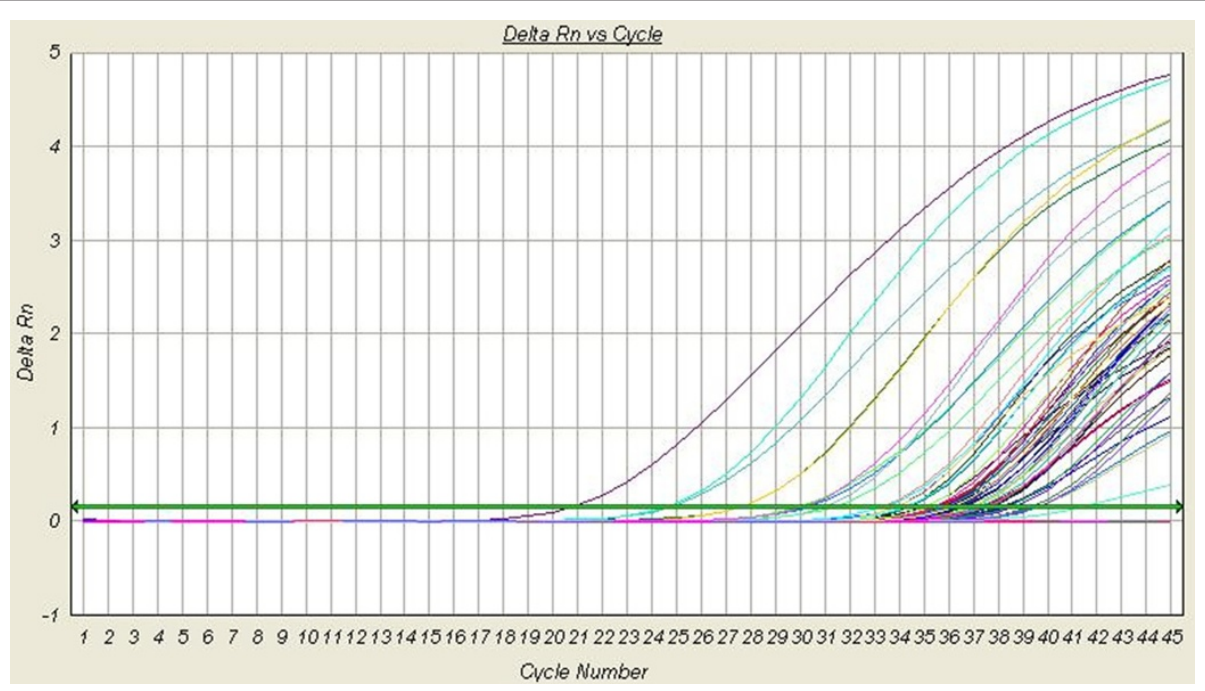

Figure 6 The selected result of clinical samples by qPCR. Selected 45 screening results for influenza A and B detection using qPCR. 


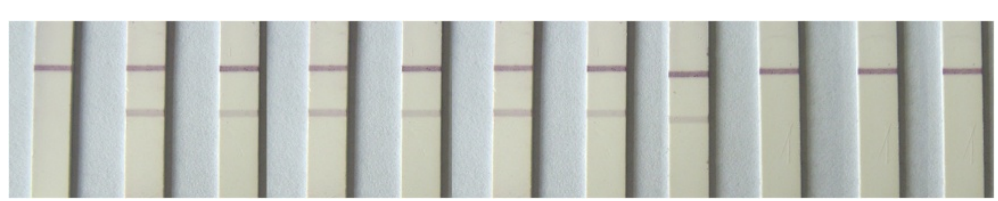

Figure 7 The selected result of clinical samples by immunochromatographic assay. Selected result screening for influenza A from 9 clinical samples. P: positive control; N: negative control.

et al. showed that the sensitivity and specificity of Seeplex RV15 DPO PCR for influenza A were $93 \%$ and $99.9 \%$, respectively, and for influenza B were $80 \%$ and $99.9 \%$, respectively [13]. Previous studies only used nasopharyngeal swabs or nasal washs, but not oropharyngeal swabs, as their main clinical sample types. The variation in sensitivity and specificity of influenza virus detection between this study and previous studies might be due to different patient sampling sites, which might result in different virus loads between the two sample panels. Commonly used clinical specimens for the detection of respiratory viruses are oropharyngeal swabs, nasopharyngeal swabs, nasal washees and sputum. However, different sampling methods may give rise to a change in the detection of influenza virus sensitivity. Li et al. indicated that nasopharyngeal swab samples may be the most effective alternative to nasal washes and oropharyngeal swab samples for the examination of respiratory viruses in adults $[14,15]$. Another study also suggested that the use of nasopharyngeal swabs was superior to oropharyngeal swabs for the detection of influenza viruses by PCR [16]. Indeed, the determination of the correct sampling site for collection of clinical specimens might be the most important factor affecting the successful detection of influenza viruses.

\section{Comparison between DPO PCR and qPCR, conventional single-target PCR and immunochromatographic assay} In this study, no significant difference in sensitivity was observed between DPO PCR and conventional PCR. Although the use of conventional primer has a low cost and

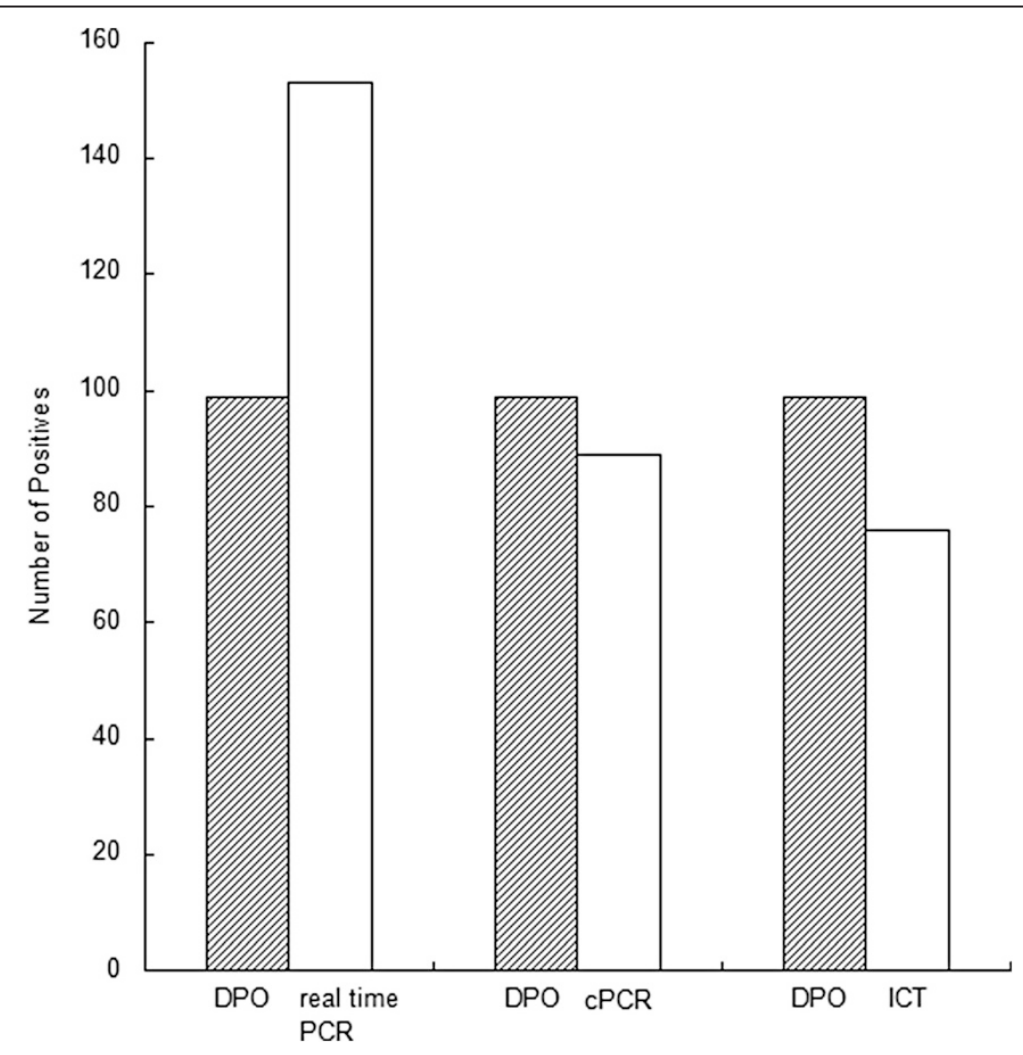

Figure 8 Comparison of three different PCR methods for all influenza A and B samples. Shaded bars represent the number of positive samples detected by DPO PCR; clear bars represent real time PCR positive samples, conventional PCR positive samples (CPCR), and positives detected by immunochromatographic test (ICT), respectively. 


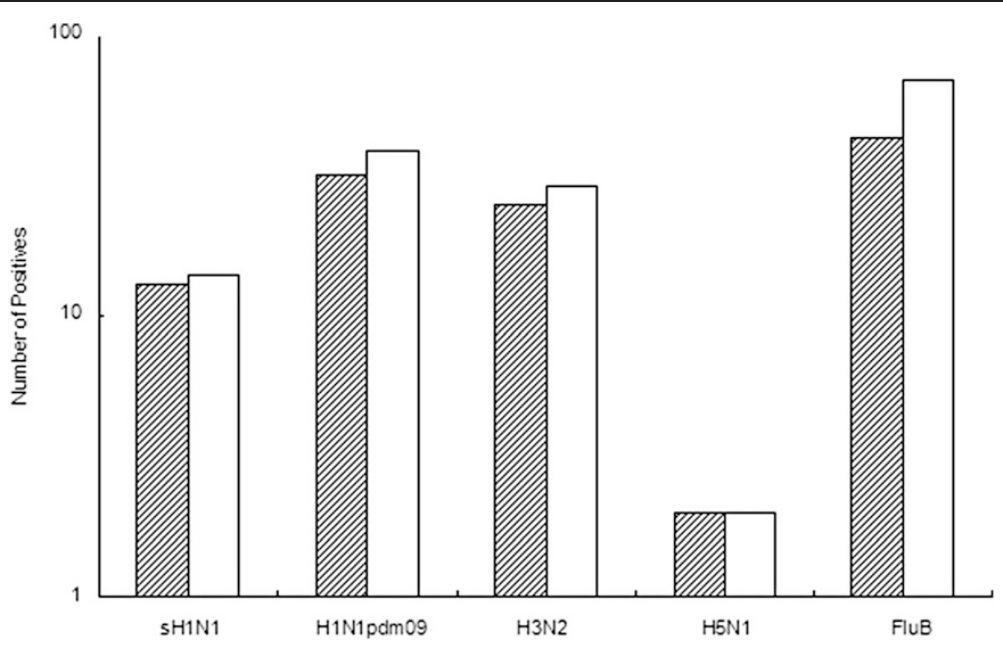

Figure 9 Comparison of DPO PCR and qPCR positive samples for sH1N1, H1N1pdm09, H3N2, H5N1 and FluB. Shaded bars represent the number of positive samples detected by DPO PCR; clear bars represent QPCR positive samples.

requires less technical training for lab technicians, this approach often produces false positive results with low sensitivity and specificity. The use of conventional primers has a number of disadvantages including primer competition, primer dimers and varing anealing temperatures required for different primers. The current use of multiplex conventional PCR requires further validation including nested PCR or probe hybridization assay to verify the results [17].

In addition to the use of PCR methods, the rapid detection of influenza virus can also be carried out using the immune colloidal gold technique supplied as commercial kits. The current study demonstrated that this rapid detection method had the lowest sensitivity and specificity for virus detection when compared with the three different PCR based methods (Figure 8).

Although qPCR is usually used as a gold standard in most laboratories to detect influenza virus, the standard Cq value should be approximately 35 to determine a positive outcome as suggested by the World Health Organization [10]. However, the World Health Organization strongly suggests that the assay should be repeated to verify the diagnostic result if the $\mathrm{Cq}$ value is in the range $30-35$ as determined by qPCR [10]. From the comparative study of positive specimens detected by $\mathrm{qPCR}$ and multiplex DPO PCR in this study, $89.3 \%$ of influenza A positive specimens were observed at a higher $\mathrm{Cq}$ range $(30<\mathrm{Cq}<35)$. The analytic results

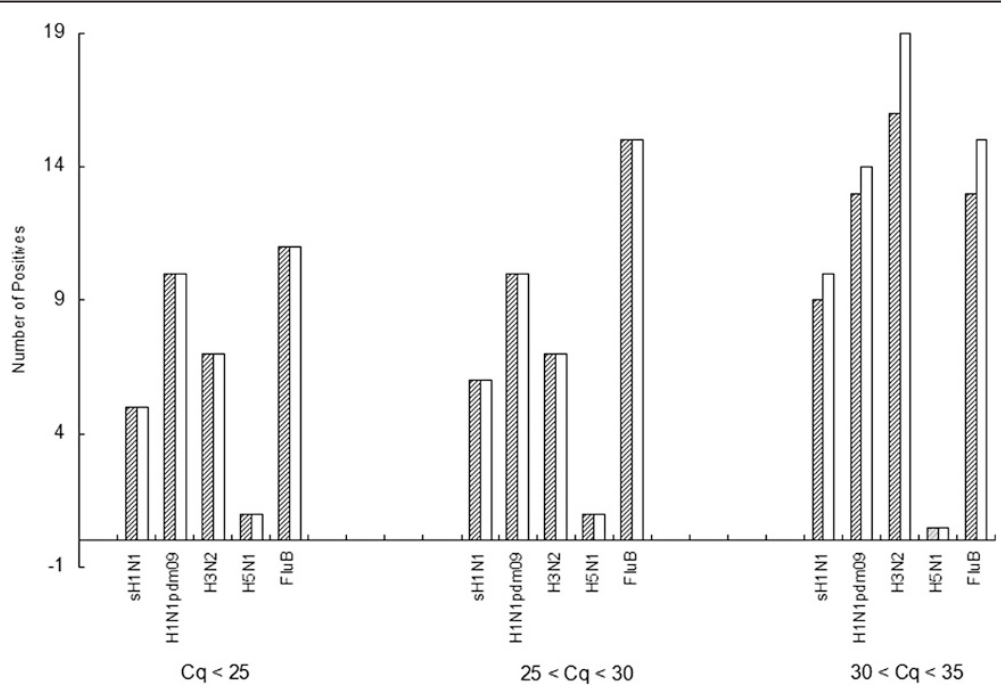

Figure 10 Comparison of positive results between DPO and qPCR in three different Cq ranges. Shaded bars represent the number of positive samples detected by DPO PCR; clear bars represent qPCR positive samples. 
from influenza B testing indicated that $96.5 \%$ samples were in the $\mathrm{Cq}$ range from 30 to 35 (Figure 10). The high percentage of qPCR positive specimens not detected by multiplex DPO PCR might have had a low target concentration or were degraded by re-freezing of the sample [4].

\section{Limitations}

The multiplex DPO PCR has some limitations. Most studies consider virus cultures and $\mathrm{qPCR}$ as a gold standard for influenza virus detection. In this study, virus culture was not available for use for all the influenza viruses detected.

\section{Conclusions}

In conclusion, the optimized multiplex DPO PCR assay provides reliable sensitivity and specificity for the detection of seasonal H1N1, 2009 pandemic H1N1, H3N2, influenza B and avian influenza H5N1. Furthermore, the sensitivity of DPO PCR was higher than for the immunochromatographic assay, lower than for qPCR and similar to conventional single PCR for the detection of influenza A and B. Multiplex DPO PCR is cost-effective, has a short running time and low technical requirements indicating its significant potential for influenza virus detection, early diagnosis and treatment in clinical laboratories.

\section{Competing interests}

The authors declare that they have no competing interests.

\section{Authors' contributions}

XM carried out the multiplex DPO PCR and drafted the manuscript. HX extracted RNA and optimized the annealing temperature and primer concentration. LS collected clinical samples. PY carried out the DPO primer design. $L Z, X S$ and $Z W$ recorded the experimental data and made the result tables. $\mathrm{KH}$ designed the study, edited the manuscript and supervised the experiment. All authors read and approved the final manuscript.

\section{Acknowledgements}

All authors read and approved the final manuscript. This study was supported by the China Mega-Project for Infectious Diseases grants (2013ZX10004-101006), (2013ZX10004202-001-006) and (2012ZX1004805008).

\section{Author details}

${ }^{1}$ Institute of Health and Quarantine, Chinese Academy of Inspection and Quarantine, INo.A3, Gaobeidian North Road, Chaoyang District, Beijing 100123, China. ${ }^{2}$ Department of Disease Control and Prevention, Shenzhen International Travel Health Care Center, Shenzhen, Guangdong Province 518045, China. ${ }^{3}$ Huaian Center for Disease Control and Prevention, No.118, Huaihai North Road, Qinghe District, Huaian, Jiangsu Province, China.

Received: 4 August 2014 Accepted: 10 February 2015

Published online: 25 February 2015

\section{References}

1. Simonsen L, Spreeuwenberg P, Lustig R, Taylor RJ, Fleming DM, Kroneman $\mathrm{M}$, et al. GLaMOR Collaborating Teams. Global mortality estimates for the 2009 Influenza Pandemic from the GLaMOR project: a modeling study. PLoS Med. 2009:2013(10):1-17.

2. Arya M, Shergill IS, Williamson M, Gommersall L, Arya N, Patel HR. Basic principles of real-time quantitative PCR. Expert Rev Mol Diagn. 2005:5:209-19.
3. Kim HK, Oh SH, Yun KA, Sung H, Kim MN. Comparison of Anyplex II RV16 with the XTAG respiratory viral panel and Seeplex RV15 fordetection of respiratory viruses. J Clin Microbiol. 2013;51:1137-41.

4. Bibby DF, McElarney I, Breuer J, Clark DA. Comparative evaluation of the Seegene Seeplex RV15 and real-time PCR for respiratory virus detection. J Med Virol. 2011;83:1469-75.

5. Kim SR, Ki CS, Lee NY. Rapid detection and identification of 12 respiratory viruses using a dual priming oligonucleotide system-based multiplex PCR assay. J Virol Methods. 2009;156:111-6.

6. Lee CS, Kang BK, Lee DH, Lyou SH, Park BK, Ann SK, et al. One-step multiplex RT-PCR for detection and subtyping of swine influenza $H 1, H 3, N 1, N 2$ viruses in clinical samples using a dual priming oligonucleotide (DPO) system. J Virol Methods. 2008;151:30-4.

7. Yoo SJ, Kuak EY, Shin BM. Detection of 12 respiratory viruses with two-set multiplex reverse transcriptase-PCR assay using a dual priming oligonucleotide system. Korean J Lab Med. 2007;27:420-7.

8. $\mathrm{Li} \mathrm{C}, \mathrm{Bu} \mathrm{Z}$, Chen $\mathrm{H}$. Avian influenza vaccines against H5N1 'bird flu'. Trends Biotechnol. 2014;432:147-56.

9. Tamura K, Peterson D, Peterson N, Stecher G, Nei M, Kumar S. MEGA5: molecular evolutionary genetics analysis using maximum likelihood, evolutionary distance, and maximum parsimony methods. Mol Biol Evol. 2011:28:2731-9.

10. WHO: WHO information for molecular diagnosis of influenza virus in humans - update. 2012.

11. Chun JY, Kim KJ, Hwang IT, Kim YJ, Lee DH, Lee IK, et al. Dual priming oligonucleotide system for the multiplex detection of respiratory viruses and SNP genotyping of CYP2C19 gene. Nucleic Acids Res. 2007;35:1-6.

12. Kim H, Hur M, Moon HW, Yun YM, Cho HC. Comparison of two multiplex PCR assays for the detection of respiratory viral infections. Clin Respir J. 2014:8:391-6.

13. Cho CH, Chulten B, Lee CK, Nam MH, Yoon SY, Lim CS, et al. Evaluation of a novel real-time RT-PCR using TOCE technology compared with culture and Seeplex RV15 forsimultaneous detection of respiratory viruses. J Clin Virol. 2013;57:338-42.

14. Li L, Chen QY, Li YY, Wang YF, Yang ZF, Zhong NS. Comparison among nasopharyngeal swab, nasal wash, and oropharyngeal swab for respiratory virus detection in adults with acute pharyngitis. BMC Infect Dis. 2013;13:281.

15. Centers for Disease Control and Prevention. Evaluation of 11 commercially available rapid influenza diagnostic tests-United States, 2011-2012. MMWR Morb Mortal Wkly Rep. 2012;61:873-6.

16. Loens K, Van Heirstraeten L, Malhotra-Kumar S, Goossens H, leven M. Optimal sampling sites and methods for detection of pathogens possibly causing community-acquired lower respiratory tract infections. J Clin Microbiol. 2009:47:21-31.

17. Hindiyeh M, Levy V, Azar R, Varsano N, Regev L, Shalev $Y$, et al. Evaluation of a multiplex real-time reverse transcriptase PCR assay for detection and differentiation of influenza viruses A and B during the 2001-2002 influenza season in Israel. J Clin Microbiol. 2005:43:589-95.

\section{Submit your next manuscript to BioMed Central and take full advantage of:}

- Convenient online submission

- Thorough peer review

- No space constraints or color figure charges

- Immediate publication on acceptance

- Inclusion in PubMed, CAS, Scopus and Google Scholar

- Research which is freely available for redistribution 